\title{
Role of Community Resiliency Model Skills Trainings in Trauma Healing Among 1994 Tutsi Genocide Survivors in Rwanda
}

\author{
Samuel Habimana' \\ Emmanuel Biracyaza (DD ${ }^{1,2}$ \\ Emmanuel Habumugisha ${ }^{3}$ \\ Evariste Museka ${ }^{4}$ \\ Jean Mutabaruka ${ }^{5}$ \\ Susanne B Montgomery ${ }^{6}$ \\ 'Rwanda Resilience and Grounding \\ Organization (RRGO), Kigali, Rwanda; \\ ${ }^{2}$ Prison Fellowship Rwanda, Kigali, \\ Rwanda; ${ }^{3}$ Department of Child \\ Development, Protection and Promotion, \\ National Child Development Agency \\ (NCDA), Kigali, Rwanda; ${ }^{4}$ National \\ Rehabilitation Service (NRS), Kigali, \\ Rwanda; ${ }^{5}$ Department of Clinical \\ Psychology, University of Rwanda, Kigali, \\ Rwanda; ${ }^{6}$ Department of Social Work \\ and Social Ecology, School of Behavioral \\ Health, Loma Linda University (LLU), \\ Loma Linda, CA, USA
}

Correspondence: Samuel Habimana

Tel +250788765133

Email samhabimana78@gmail.com
Background: Mental health among survivors of the 1994 Tutsi genocide in Rwanda remains poor, even after multiple efforts to assist those recovering from this trauma. The Community Resilience Model (CRM) is a biologically based set of skills that can be delivered in community settings by trained lay persons and has shown to significantly improve mental health in a number of settings and populations, though it has not been used with genocide survivors in Rwanda. This study assessed if the CRM training was able to improve mental health among genocide survivors.

Methods: A quasi-experimental design was used to evaluate the CRM intervention among Tutsi genocide survivors from the Huye, Nyamagabe and Nyaruguru districts in Southern Rwanda. Consenting participants completed a questionnaire before and six months after the training to assess their level of trauma, secondary traumatic stress, depression and skills to teach CRM skills to others.

Results: The findings revealed significant improvements across all trauma symptoms between the intervention and control group $(\mathrm{t}=37, p<0.001)$. The CRM trainings also resulted in significant within-person declines of depressive symptoms $(\mathrm{p}<0.001)$, perceived secondary traumatic stress $(\mathrm{p}=0.003)$ and trauma-related symptoms $(\mathrm{p}=0.002)$. Training participants also reported significant increases in perceived CRM benefits and satisfaction $(p<0.001)$.

Conclusion: The CRM intervention was found to be effective for improving mental health in 1994 Tutsi genocide survivors. Since CRM can be delivered by trained persons to groups of persons in community settings, it has a high potential for successful broader implementation and sustainability, which is critically important in an environment with few mental health resources.

Keywords: community resilience model, resilience, genocide survivor, trauma healing

\section{Background}

A genocide is the systematically killing of masses of people with the intention of destroying the identity of the targeted groups and is often racially or religiously motivated. ${ }^{1,2}$ The effects of genocide are broad and in addition to those who were killed, continue to effect the wellbeing of individuals, families and communities maimed in the 1994 Tutsi genocide in Rwanda (Tutsi genocide). ${ }^{3,4}$ Tutsi genocide survivors continue to re-experience these traumatic events as they occurred in their communities and the traumatic reminders of the horrors they experienced are ever present and as a result significantly impact their psychosocial wellbeing. Often neighbors, former associates, and friends were the perpetrators, and seeing them on a regular 
basis leads to re-experiencing the events, resulting in flashbacks, phobias, substance use and chronic headaches. ${ }^{5}$ The prevalence of posttraumatic stress disorders (PTSD) in the years that followed the Tutsi genocide varied between 50 and $60 \%$ among children and were measured at $41.4 \%$ or more among widows who either witnessed or survived these horrible events. ${ }^{6}$ After the Tutsi genocide, the country was depleted of many resources as many were killed and others fled to never return as there were few behavioural health services. ${ }^{7}$ Most Tutsi genocide survivors either experienced or witnessed torture or had experienced the threat of being tortured and/or killed. As a result, the psychological effects of the genocide remain high, especially as Rwanda lacked sufficient mental health service providers to assist the many Tutsi genocide survivors. ${ }^{7}$

Prior studies indicate that the effects of the genocide are broader than the direct effects on the survivors. It also affects their descendants as well as the genocide perpetrators and their descendants. Individuals who experienced the genocide, including descendants who were born during or after genocide, are experiencing significant mental disorders, including post-traumatic stress, anxiety, and depression. ${ }^{8,9}$ For instance, in a recent survey conducted on genocide survivors and their offspring found that offspring from parents with PTSD also reported a high prevalence of secondary traumatization symptoms. ${ }^{10}$ To combat the psychological effects of the Tutsi genocide, a number of interventions were implemented to help improve the psychological health of the Tutsi genocide survivors. As much as they could public and private institutions provided professional counselling, and peer-to-peer counselling as well as health supports, with the purpose of reducing the severity of trauma, anxiety, depressive and other psychosocial effects in the genocide survivors. These approaches also set out to restore humanisation, personal growth, self-esteem, and dignity. For instance, the community-based sociotherapy or MvuraNkuvure and restorative justice were applied and resulted in significant reductions of psychiatric disorders, such as depression, anxiety and trauma. ${ }^{8,11,12}$ However, more than 25 years since the Tutsi genocide, many still suffer from the aftereffects and few resources reach them.

As a country, Rwanda has showed tremendous resilience working hard to move on from these horrific events. Resilience refers to an ability of an individual to bounce back from traumatic events so that they can maintain a stable level of functioning. It is an individual's utilization of inner strengths and external resources to overcoming trauma. ${ }^{13}$ Community resilience, on the other hand, is the ability of an affected community to withstand and recover from shared community stressors, learn from them and as a result to build internal strength to not only move on but also be prepared for other stressors that may arise. It is needed to power needed changes to improve community health and the remaining social and economic systems. Thus, both individual and community resilience is needed for a society to continue functioning properly after traumatic events. ${ }^{14}$

Resilience is complex and in part occurs because of positive functional adaptations in the brain, ${ }^{15}$ although it depends on genetic, epigenetic, neural, and environmental factors-which are mediated by adaptation in neural circuits, neurotransmitters, and molecular pathways. ${ }^{16,17}$ Increasing resilience levels by using different therapies could be an important way to promote psychological wellbeing of affected people. Given this biological basis of resilience, the Community Resilience Model (CRM) was developed with this in mind and sets out to help participants learn a set of self-help skills to increase their ability to respond to stress.

In identifying factors or interventions which can build resilience, an important component which has shown promise is "neurobiological" practices, which has been defined as "movement, breathing, and meditation techniques that engage the body, mind, and emotions for healing and recovering from trauma". ${ }^{18} \mathrm{CRM}$ is based on these principles and refers to an innovative, preventive and mental wellness intervention. It was originally developed for post-disaster settings to promote psychological resilience in individuals and communities affected by the traumatic events. ${ }^{19} \mathrm{CRM}$ skills are self-regulation skills that draw on the internal and external sensory perceptions of the individuals ${ }^{20,21}$ and involve learning a set of six wellness skills built on our understanding of the "normal" response of the human nervous system to stress and trauma. ${ }^{22}$ Developed by Elaine Miller-Karas from the Trauma Resource Institute (TRI), CRM aims to reset the nervous system's natural balance after trauma experience. ${ }^{23}$ CRM's draws on well-established somatic and sensory motor psychotherapies that were simplified and adapted for delivery by trained lay educators in low resourced settings. It involves the use of easily teachable skills that are used to track one's sensations to external or internal stimuli and learn to control them to improve one's well-being. With practice, CRM skills can help bring the nervous system back into equilibrium, helping individuals 
strengthen their resilience. Since it can be delivered by lay professionals with low cost across a variety of settings in the community, it presents a sustainable model, a critical issue in under-resourced environments. ${ }^{24}$

The three core CRM skills are tracking, resourcing and grounding. Tracking, or noticing sensations within the body, is one of the skills used with the other CRM skills for promoting resiliency for a person's nervous system. Using tracking, an individual learns to differentiate pleasant or neutral sensations. Resourcing is a skill aiming to help people identify and use positive things considered as their resources. Participants are taught to recall their potential resources and then encouraged to track the resulting positive sensations that occur when a person thinks about this resource. With practice, asking questions that add more details to the resource, thereby deepening the sensation connected with the resource, can intensify these resources. Grounding, or the direct contact of the body with solid surfaces that provides support to the body, provides gravitational security and is applied when the person brings awareness to how the body is physically supported in the present moment. The sensory attention to the here and now stimulates an observable and sensed parasympathetic response in the nervous system.

These core skills are augmented by three additional skills that can be used depending on the situation. The "gesturing" skill helps people to tap into a natural human tendency to make gesture as they experience emotions. Intentionally used, this skill can help regulate the nervous system responses of the participants in the moment. Similarly, "help now" skills are used when someone is highly activated, by distracting them from immediate stressors. Finally, "shift and stay" skills help a person learn to shift his attention from something unpleasant to something neutral or pleasant and staying there. One could, for instance, offer a highly activated person a glass of water, may name colors in the room, or push their hands against a wall slowly to notice one's muscle response. $^{22}$

The set of skills taught in the CRM intervention helps the participants learn to regulate their autonomous nervous system through an awareness of the sensation in the human body. While learning a set of skills to help address stress reactions, participants learn to track sensations connected to their resilience and understand the biology of their stress or trauma reactions in their daily life. $^{25}$ The skills are easily learned and when practiced have been found to help enhance resiliency and one's ability to withstand stress. ${ }^{21}$ For instance, in a recent randomized controlled study CRM reduced depression, anxiety and secondary traumatic stress, in nurses ${ }^{22}$ and in another study was able to improve depression and anxiety in a high violence, high need community setting across a variety of participant groups. Studies using CRM have resulted in reduced anxiety, depression, somatic complaints and hostility, ${ }^{26}$ and have helped individuals with severe trauma. ${ }^{27}$ Other studies were conducted with war veterans, victims of domestic violence, substance users, and health professionals. ${ }^{28}$ These studies have demonstrated the effectiveness of CRM to attenuate symptoms of depression, anxiety and PTSD and increase resilience, ${ }^{23}$ and CRM has been applied in many post-disaster settings. Despite its potential to help those who experienced traumatic events, ${ }^{29,30}$ it has not been rigorously evaluated internationally, and no studies have been conducted in subSaharan African countries, including Rwanda. This study, therefore, seeks to explore the use of CRM for reducing trauma and depression symptomatology among the Tutsi genocide survivors in Rwanda.

\section{Methods}

\section{Sample and Procedure}

The present study was conducted from January to June 2016 and used a quasi-experimental waitlist design. The CRM skill training was delivered to 130 Tutsi genocide survivors (73 females and 57 males, aged 25-65, mean age $=47, \mathrm{SD}=8$ ). The control groups were 120 genocide survivors (67 females and 53 males, aged 25-65, mean age $=39, \mathrm{SD}=12$ ) who received the $\mathrm{CRM}$ training once the study was completed. Participants were Tutsi genocide survivors from the Huye, Nyaruguru and Nyamagabe districts in Southern Rwanda. The counselors of Rwandan Association of Genocide Widows (AVEGAAGAHOZO) and the National Commission for Fight against Genocide (CNLG) helped in recruitment of participants. The inclusion criteria were being genocide survivor known by local leaders, presenting with trauma symptoms, and having lost at least one family member during the 1994 genocide against Tutsi.

\section{Measures Translation}

Three English- and Kinyarwanda-speaking psychologists conducted the back-and-forth translation of the questionnaires from English to Kinyarwanda, a local language known by all Rwandans. It was then pilot tested for 
acceptability and comprehension. The questionnaire was made up of mainly validated scales and a demographic section. Psychometric instruments were completed at the baseline before the CRM intervention, and again six months after the implementation of the CRM.

\section{Data Collection}

All persons delivering the intervention were trained by the pioneer of this intervention, Elaine Muller-Karas (founder of the Trauma Resource Institute (TRI)). These trainees then delivered the intervention and administered the surveys to participants. The training was provided in the comfortable settings within the communities where the participants reside. Depending on participants' residence, each participant received the transport fees (USD 2.50) at the time of participation in the study.

\section{Materials}

To assess the socio-demographic background of the participants, we looked at gender (male/female), age (categorical), marital status (single, married, widowed, separated/ divorced), and education (illiterate, primary level, secondary level or higher). In addition to the demographic questions, we used psychometric instruments that had been validated in international settings, including the Harvard Trauma Questionnaire (HTQ), Patient Health Questionnaire-9 (PHQ), Secondary Trauma Stress Scale (STSS) and the Community Resiliency Model Skills Questionnaire (CRMQ).

The Harvard Trauma Questionnaire (HTQ) is 40 items, self-report scale assessing trauma experiences that we adapted to the Rwandan context. Each item was scored from 1 (none) to 5 (extremely) and the total score indicated the participants' degree of PTSD symptoms. The Cronbach's Alpha for our sample was $0.80 .^{31}$

The Patient Health Questionnaire-9 (PHQ-9) is a 9-item scale used to assess depressive symptoms in the 2 past weeks. Each item is scored from 0 (not at all) to 3 (every day). In our study, the Cronbach's Alpha was $0.81 .^{32}$

The Secondary Traumatic Stress Scale (STSS) has 17 items, and it was used to measure the severity of the secondary trauma. Each item was scored from 1 (never) to 4 (often). Higher score means more severe and lower score means less severe traumatic stress. The Cronbach's Alpha was 0.81 in our sample. ${ }^{33,34}$

The Community Resiliency Model skills Questionnaire (CRMQ) comprises two parts, one about satisfaction/ usefulness of the self-care (CRM) training (29 items), and the other assessing the benefits of the training (3 items). ${ }^{25,26}$ The items of satisfaction were scored from 1 (poor) to 5 (excellent) while for benefits 1 (disagree) to 5 (agree). Higher scores indicate higher levels of satisfaction/perceived benefits, whilst lower scores indicate lower such level. The Cronbach's Alpha was 0.75 in our sample for both satisfaction and benefits.

\section{Data Analysis}

Descriptive analysis described the participants using statistical parameters such as frequency, mean, median, and standard deviation. We also used paired sample-test to test within-group differences before and after the intervention. The repeated measures or split-plot analysis of variances was applied to indicate the influences of the sociodemographic variables on psychological wellbeing promotion. Once we established that our outcome variables were normally distributed, ${ }^{35}$ the independent samples $t$-test was performed to compare the means of two independent groups (pre- and post-test) in order to determine whether there is statistical evidence that the associated population means are significantly different. Data analysis was performed according to the intention-to-treat principle, ie, special care was taken to gather follow-up data on all research participants. A one-way ANOVA was performed using independent $t$-test to measure any differences between the intervention and comparison groups controlling for the influence of sociodemographic. Cut-offs for the psychometric instruments to determine the presence of symptomatology were conducted with scores of $\geq 2.5$ for HTQ, $\geq 13$ for PHQ and $\geq 44$ for STSS. All descriptive and analytical statistical analyses were performed using STATISTICA version 13.

\section{Intervention}

The CRM training ${ }^{22,25}$ was delivered over four days (7 hours per day) to groups of 25-30 participants; all were Tutsi genocide survivors. Participant trainees practiced each skill in small groups and at the end of the training were evaluated for their ability to apply and teach the CRM skills to others. Comparison group participants were offered a waitlist, delayed training after the post-test.

\section{Ethics}

The approval for conducting the research was obtained from the Rwanda Governance Board through permission provided by the local leaders at the district and sector levels. In accordance with the Declaration of Helsinki to assure the 
conduct of ethical research informed consent was obtained for all participants before the training and data collection by first verbally explaining the procedure, confidentiality and voluntary participation, followed by time for questions and written informed consent. Moreover, the study was retrospectively registered with the WHO.

\section{Results}

Table 1 illustrates the demographic characteristics of intervention and comparison between the groups of participants. Neither gender nor age differed significantly between the groups. Both groups had more female than male participants $(56.1 \%$ and $55.8 \%$, respectively) and both intervention and control group participants were aged between 41 and 50 (55.7\% and 47.9\%, respectively). With respect to education, the groups differed significantly $(p<0.001)$; the intervention group was significantly more likely to be illiterate ( $62.7 \%$ vs $21.2 \%$, respectively), while the control group had significantly higher levels of education. Marital status differed significantly $(\mathrm{p}<0.001)$ between the two groups, with more persons in the intervention group were widowed (63\% vs $33 \%)$, while the

Table I Demographic Characteristics of Participants

\begin{tabular}{|c|c|c|c|}
\hline Characteristics & $\begin{array}{l}\text { Intervention } \\
\text { Group N (\%) }\end{array}$ & $\begin{array}{l}\text { Comparison } \\
\text { Group N (\%) }\end{array}$ & p-values \\
\hline \multicolumn{4}{|l|}{ Sex } \\
\hline Female & $73(56.1)$ & $67(55.8)$ & 0.118 \\
\hline Male & $57(43.9)$ & $53(44.2)$ & \\
\hline Age, mean (SD) & $42(13.7)$ & $38.9(6.8)$ & \\
\hline \multicolumn{4}{|l|}{ Ages } \\
\hline $25-30$ & $21(16.2)$ & $20(16.7)$ & 0.621 \\
\hline $31-40$ & $3 I(23.8)$ & $3 I(25.8)$ & \\
\hline $4 I-50$ & $57(43.8)$ & $56(46.7)$ & \\
\hline $5 I-65$ & $21(16.2)$ & $13(10.8)$ & \\
\hline \multicolumn{4}{|l|}{ Education } \\
\hline Illiterate & $82(62.7)$ & $12(2 \mid .2)$ & $0.005^{*}$ \\
\hline Primary level & $3 I(24)$ & $61(52)$ & \\
\hline $\begin{array}{l}\text { Secondary or } \\
\text { higher }\end{array}$ & $17(13.3)$ & $32(26.8)$ & \\
\hline \multicolumn{4}{|l|}{ Marital status } \\
\hline Single & $3(2)$ & $37(31)$ & $<0.001 * *$ \\
\hline Married & $22(24)$ & $32(27)$ & \\
\hline Widower & $82(63)$ & $40(33)$ & \\
\hline $\begin{array}{l}\text { Separate/ } \\
\text { divorced }\end{array}$ & $14(11)$ & II(9) & \\
\hline
\end{tabular}

Notes: *Statistical significance at $p<0.05$; * high statistical significance at $p<0.001$ Abbreviation: SD, standard deviation. comparison group participants were more likely to be single (31\% vs $2 \%$ ) or married ( $27 \%$ vs $17 \%$ ) (Table 1$)$.

The analysis of one-way ANOVA was applied using independent $t$-test for assessing any baseline differences between the experimental and control groups for sociodemographic characteristic correlations with our mental health variables.

In this study, four variables were analyzed to explore their correlation with demographic variables: perceived secondary traumatic stress (STSS); trauma symptomatology (HRQ); and depression severity (PHQ-9). For the intervention group, the results showed significant correlations of our demographic variables with these outcomes. Namely, sex $(\mathrm{F}=28.63, \mathrm{p}<0.001)$, education $(\mathrm{F}=4.7, \mathrm{p}<0.032)$, age $(\mathrm{F}=24.96, \mathrm{p}<0.001)$ and marital status $(\mathrm{F}=6.02, \mathrm{p}=0.004)$ were significantly correlated with depression. Similarly, there were significant correlations of our demographic variable with our outcomes on secondary traumatic stress (STSS), namely sex $(\mathrm{F}=25, \mathrm{p}<0.001)$, age $(\mathrm{F}=64.3, \mathrm{p}<$ $0.001)$, education $(\mathrm{F}=4.4, \mathrm{p}=0.04)$ and marital status $(\mathrm{F}=$ 9.6, $\mathrm{p}=0.0033)$ and $\operatorname{sex}(\mathrm{F}=0.1, \mathrm{p}=0.03)$, education $(\mathrm{F}=6$, $\mathrm{p}=0.02)$, age $(\mathrm{F}=16, \mathrm{p}<0.001)$ and marital status $(\mathrm{F}=5.07$, $\mathrm{p}=0.026)$ on trauma symptomatology. The statistical analyses also found significant influences of $\operatorname{sex}(\mathrm{F}=0.9, \mathrm{p}=$ 0.014), age $(\mathrm{F}=17.4, \mathrm{p}<0.001)$, education $(\mathrm{F}=6.3, \mathrm{p}<$ $0.001)$ and marital status $(\mathrm{F}=13, \mathrm{p}<0.001)$ on the benefits from CRM skills. Notably, for our control group participants, except for marital status on STSS ( $p<0.05$ ), no significant interaction of age, gender, education and marital status on depression perceived secondary traumatic stress and trauma symptoms (Table 2).

Table 3 summarizes the mean differences in the mental health outcome variables in the control and experimental groups for pretest and post-test. For our intervention participants, across all indicators, a significant reduction of symptoms of trauma $(\mathrm{t}=79.6, \mathrm{t}=0.002)$, perceived stress $(\mathrm{t}=25.4, \mathrm{p}=0.003)$ and depression $(\mathrm{t}=6.19, \mathrm{p}<0.01)$ were found. This indicates that the CRM intervention resulted in significant improvements at 6 months. Participants in the control group at the six-month follow-up presented with a marginally significant increase of perceived stresses $(\mathrm{t}=0.18, \mathrm{p}=0.0859)$, trauma symptomatology $(\mathrm{t}=1.7, \mathrm{p}=$ $0.105)$ and depression $(\mathrm{t}=1.9, \mathrm{p}=0.059)$. Our results showed that the genocide survivors who were not assigned to the CRM skills at 6 months post the baseline measurement were more likely to have a slight increases in symptoms of depressive disorders, perceived secondary traumatic stresses and trauma symptomatology. 
Table 2 Influences of the Socio-Demographic Characteristics on Baseline Mental Health of Participants

\begin{tabular}{|c|c|c|c|c|}
\hline \multirow[t]{2}{*}{ Characteristics } & \multicolumn{2}{|c|}{$\begin{array}{l}\text { Comparison } \\
\text { Group }\end{array}$} & \multicolumn{2}{|c|}{$\begin{array}{l}\text { Intervention } \\
\text { Group }\end{array}$} \\
\hline & $\mathbf{F}$ & $p$-value & $\mathbf{F}$ & $p$-value \\
\hline \multicolumn{5}{|c|}{$\begin{array}{l}\text { Depressive symptoms } \\
\text { (PHQ9) }\end{array}$} \\
\hline Sex & 3.48 & 0.064 & 28.63 & $<0.001^{* *}$ \\
\hline Age & 1.2 & 0.276 & 24.96 & $<0.00 I^{* *}$ \\
\hline Education & 0.75 & 0.388 & 4.7 & $0.032 *$ \\
\hline Marital status & 0.56 & 0.454 & 6.02 & $0.004 *$ \\
\hline \multicolumn{5}{|c|}{$\begin{array}{l}\text { Perceived secondary } \\
\text { traumatic stress (STSS) }\end{array}$} \\
\hline Sex & 2.5 & 0.11 & 25 & $<0.00 I^{* *}$ \\
\hline Age & 1.5 & 0.222 & 64.3 & $<0.00 I^{* *}$ \\
\hline Education & 1.65 & 0.201 & 4.4 & $0.04 *$ \\
\hline Marital status & 5.07 & $0.026 *$ & 9.6 & $0.0033^{*}$ \\
\hline \multicolumn{5}{|c|}{$\begin{array}{l}\text { Trauma symptoms } \\
\text { (HTQ) }\end{array}$} \\
\hline Sex & 0.35 & 0.276 & 0.1 & 0.03 \\
\hline Age & 0.13 & 0.725 & 16 & $<0.00 I^{* *}$ \\
\hline Education & 2.59 & 0.11 & 6 & $0.02 *$ \\
\hline Marital status & 0.35 & 0.558 & 5.07 & $0.026^{*}$ \\
\hline \multicolumn{5}{|c|}{$\begin{array}{l}\text { Satisfaction with self-care } \\
\text { and Benefits of CRM } \\
\text { training (CRMQ) }\end{array}$} \\
\hline Sex & NA & NA & 0.9 & $<0.014^{*}$ \\
\hline Age & NA & NA & 17.4 & $<0.001 * *$ \\
\hline Education & NA & NA & 6.3 & $<0.001 * *$ \\
\hline Marital status & NA & NA & 13 & $<0.00 I^{* *}$ \\
\hline
\end{tabular}

Notes: *Statistical significance at $p<0.05$; **high statistical significance at $p<0.001$. Abbreviations: CRM, Community resilience model; CRMQ, Community resilience model Questionnaire; F, F-test used for assessing analysis of variance; NA, Not applicable as respondents from control group were not assigned to CRM skills questions.

Only intervention group participants were evaluated for perceived benefits of self-care and satisfaction with CRM training (see Table 4). We found statistically significant benefits from attending the CRM trainings with significant increase of satisfaction with self-care (CRM skills) and perceived benefits of self-care (CRM) skills, with the overall benefits of self-care skills mean significantly shifting from 5.6 to $11.9(\mathrm{p}<0.001)$. The results for satisfaction with using self-care (CRM) skills increased from $\mathrm{M}=52.59$ at pre-test to a 6-month post-test score of 104.9 ( $\mathrm{p}<0.001)$.

\section{Discussion}

The objective of this study was to assess the long-term effects of the CRM skills intervention on trauma healing between two community groups of 1994 Tutsi genocide survivors. One served as the intervention group, the other served as a comparison group and received the intervention after the study was completed (waitlist comparison). As expected, both the intervention and comparison group presented with high baseline levels of depressive symptoms, perceived stress and trauma symptoms. These results are corroborated by previous studies that also found that despite the fact that the genocide occurred more than 20 years ago, Rwandese genocide survivors still present with high rates of PTSD and other related psychological symptoms. ${ }^{2,4,36}$ This may in part be explained by the severe trauma survivors experienced and the relative lack of professional or even community program resources in Rwanda to address this need for post-Tutsi genocide mental health care. Clearly, interventions are needed to address these stubbornly persistent trauma experiences in the Tutsi genocide survivors. It is in this context that we set out to explore if a communitybased group delivery approach, that teaches a set of selfregulation skills (CRM skills) designed to counteract one's natural biological response to trauma, would be useful in addressing some of these needs.

Similar to studies conducted in the United States (US), ${ }^{2,21}$ our results revealed that teaching participants the CRM skills resulted in a significant improvement in depressive, perceived stress and trauma symptoms among the participants who attended the CRM trainings. In other

Table 3 Pre- and Post-Intervention Trauma, Depression, and Perceived Stress Intervention versus Control Group Participants

\begin{tabular}{|c|c|c|c|c|c|c|c|c|}
\hline \multirow[t]{3}{*}{ Tool } & \multicolumn{4}{|c|}{ Intervention $(\mathrm{N}=130)$} & \multicolumn{4}{|c|}{ Comparison Group $(\mathrm{N}=120)$} \\
\hline & Pretest & Posttest & $\mathbf{t}$ & $p$-value & Pretest & Posttest & $\mathbf{t}$ & $p$-value \\
\hline & Mean (SD) & Mean (SD) & & & Mean (SD) & Mean (SD) & & \\
\hline HTQ & $65.55(12.85)$ & 49.05 (II.54) & 79.6 & $0.002 *$ & $82.28(15.07)$ & $97.49(13.16)$ & 1.7 & 0.105 \\
\hline PHQ & $20.11(3.48)$ & $10.57(6.7)$ & 6.19 & $<0.001 * *$ & $13.15(1.13)$ & I7.6I (I.39) & 1.9 & 0.059 \\
\hline STSS & $56.23(10.95)$ & $26.95(6.729)$ & 25.4 & $0.003^{*}$ & $25.94(4.73)$ & $37.62(6.209)$ & 0.18 & 0.0859 \\
\hline
\end{tabular}

Notes: *Statistical significance at $p<0.05$, $* *$ High statistical significance at $p<0.00$ I.

Abbreviation: $t$, $t$-test. 
Table 4 Comparison Between Baseline and 6-Month Follow-Up Benefits-Satisfaction Results in the Intervention Group

\begin{tabular}{|l|l|c|c|}
\hline \multicolumn{2}{|l|}{ Scale } & M & SD \\
\hline Benefits CRMQ (3 items)*** & Baseline perceived benefits of self-care skills & 5.6 & 1.455 \\
& Follow-up perceived benefits of self-care skills & 11.9 & 1.18 \\
\hline Satisfaction CRMQ (29 items)*** & Baseline satisfaction with self-care skills & 52.5 & 7.63 \\
& Follow-up satisfaction with self-care skills & 104.9 & 11.43 \\
\hline
\end{tabular}

Note: ***High statistical significant at $p<0.001$.

Abbreviation: CRMQ, Community Resilience Model Questionnaire.

words, we found that the CRM intervention was indeed able to significantly improve all measured mental health symptoms in our genocide survivors. Moreover, while our comparison group at baseline presented with less severe symptoms of stress and depressive symptoms, they presented with worsening symptoms at the six months posttest and their trauma symptoms, while higher at baseline continued to get worse over time.

A unique aspect of CRM is that it does not require trained mental health professionals and can be used to build the capacity of community trainers who, in turn, can reach out and deliver the intervention to others in need. ${ }^{25}$ Moreover, the focus on human biology being responsible for a "normal" response to trauma resulting in depression, anxiety and other symptoms of distress, relieves the participants of the potential stigma of seeking help for those problems. ${ }^{16}$

Consistent with earlier studies that documented that CRM trainings contribute to the improvement of quality of life, resilience, reduction of physical symptoms and healing trauma, ${ }^{16,21,37}$ the results of the current study revealed that participants in the training at six months post-intervention delivery felt strong benefits and satisfaction with the skills they learned. These results suggest that the CRM skills intervention is a promising approach to addressing trauma symptoms in the context of Rwandese genocide survivors.

While we did not conduct mechanistic studies differentiating how the six CRM skills work, we believe that the tracking skill, as a core skill might specifically be helpful regarding somatization symptoms. Learning how to track one's physical sensations related to stress and also how one can use the CRM skills of resourcing and grounding to pivot away from such activation helps participants to more successfully manage their reactions to everyday stressors that would have formerly affected them more negatively. During the training participants learn how to differentiate how one's resources or positive memories as well as grounding oneself can intentionally be used to create a shift away from negative reactions when confronted with a stressor or negative traumatic memory. As such, tracking can help participants bring to conscious awareness their "usual" reactions to life experience using the portal of the body. ${ }^{25}$ This awareness can be a first step toward healing as it allows some control over an often purely reactive response.

While nothing can take away the horrific experiences of the Tutsi genocide survivors, the skills taught as part of the CRM training can help turn to aspects of happiness in their lives instead of focusing on the stressful negative past experiences. Resource skill builds internal resiliency and renews a sense of one's own ability and capacity to selfhelp and stabilize one's nervous system. Grounding skill supports these efforts as it reminds a person that they are present in the here and now and are not bound to the memories of past experiences. In this sense, grounding skill might help participants to at least get back in a neutral balance versus a negative state. In conjunction with the other skills, these core skills of tracking, resourcing and grounding, regardless of culture, can help bring positive feelings of calm and strength to participant's wellbeing. ${ }^{25}$

\section{Study Limitations}

There are several limitations to our study that should be noted. While we had a comparison group design, our overall sample size was modest, and there was no random assignment. In the African context, good news is shared freely, making random assignment within a given community impossible. As a result, we chose a comparison waitlist design which made a longer than six-month follow-up impossible, as the comparison participants eagerly awaited their turn to participate in the intervention. By chance, our control group turned out to be higher educated, and less likely to be widowed, and these differences were more likely to be correlated with our mental health measures in 
the intervention group. Also, the control group participants reported significantly less severe symptomology for stress and depression and higher trauma symptom scores. Notably, however, all measures got slightly worse over time for the comparison group, while the intervention group improved. Despite these limitations, we see this study as an important first step in determining the effectiveness and feasibility of the CRM training approach for Rwandan genocide survivors. Indeed, not only did our intervention group present with consistently better mental health outcomes at six months after the training, they also reported high acceptability, benefits and satisfaction of the CRM intervention approach to their self-management of stress. In light of these limitations, we suggest future studies to use site randomization, a larger sample size and a longer follow-up to confirm our strong results. We also suggest expanding the study measures to include measurements of resilience and allow for an exploration of qualitative testimonies about the changes participants observed in their functioning over time.

\section{Conclusion}

As postulated, our CRM trainings were helpful in trauma healing and in improving participant's mental health. Our findings were consistent with previous research indicating that CRM skills are effective to expand one's resilience zone and to make traumatized people more resilient in order to heal their trauma symptoms. CRM skills for our participants helped them renew their sense of ability and capacity for self-help through a sense of being present in the here and now, and on the ability to shift away from traumatic memories to more neutral and/or positive sensations. After the training, many of our participants told us that they were interested in not only practicing the skills but also to share the model. Especially in low resourced settings with much trauma and little professional assistance, this model offers a promising option to efficiently serve affected communities in their healing from trauma using trained community members, a key issue for the promise of sustainability. While we suggest further research into the CRM model, we wish to also acknowledge the continuing need for mental health interventions that are effective and feasible. We, therefore, recommend that the CRM intervention should be more broadly delivered in Rwanda, especially to help with a more effective reintegration of the prisoners who committed genocide which is scheduled to occur and is leading to high stress in the survivors of the genocide.

\section{Data Sharing Statement}

The datasets analyzed during the current study are available from the corresponding author on reasonable request.

\section{Ethics Approval and Consent to Participate}

The current study was ethically approved by concerned institutions under the authorization of the local leaders at district level. In addition, written informed consent was obtained from all participants ahead of their participation.

\section{Acknowledgments}

We gratefully thank the local leaders at district, sectors levels, staff of AVEGA and CNLG at district level for permitting us to conduct this study. We also appreciate Trauma Resource Institute (TRI) for introducing CRM skills in Rwanda. We thank the participants for their invaluable time and contributions in this study. We also thank Dwight M. Montgomery ESQ for reading, editing and reviewing the current manuscript as an expert in these domains.

\section{Author Contributions}

All authors made substantial contributions to conception and design, acquisition of data, or analysis and interpretation of data; took part in drafting the article or revising it critically for important intellectual content; agreed to submit to the current journal; gave final approval of the version to be published; and agreed to be accountable for all aspects of the work.

\section{Funding}

The research had no funding.

\section{Disclosure}

The authors declared no conflicts of interest in this work. This manuscript was presented at the fourth International Conference on resilience that occurred from 20th to 30th June 2018 in Marseille, France as a poster presentation with interim findings. The poster's abstract was published in https://hal.archives-ouvertes.fr/hal-02465380. This presentation was published as a chapter entitled "Role of Community Resiliency Model (CRM) skills trainings in trauma healing among 1994 Tutsi genocide survivors in Rwanda" in the book entitled "Pratiques Basées sur la Résilience". The manuscript that was presented may be accessed using: https://horizon.documentation.ird.fr/exldoc/pleins_textes/divers20-02/010077589.pdf; or https:// hal.archives-ouvertes.fr/hal-02465380. 


\section{References}

1. Fein H. Social recognition and criminalization of genocide. Curr Sociol. 1990;38(1):1-7. doi:10.1177/001139290038001003

2. Mutabaruka J, Séjourné N, Bui E, Birmes P, Chabrol H. Traumatic grief and traumatic stress in survivors 12 years after the genocide in Rwanda. Stress Health. 2012;28(4):289-296. doi:10.1002/smi.1429

3. Banyanga J, Björkqvist $\mathrm{K}$. The dual role of religion regarding the Rwandan 1994 genocide: both instigator and healer. Pyrex J Afr Stud Dev J Afr Stud Dev. 2017;3(2):1-12.

4. Dyregrov A, Gupta L, Gjestad R, Mukanoheli E. Trauma exposure and psychological reactions to genocide among Rwandan children. $J$ Trauma Stress. 2000;13(1):3-21. doi:10.1023/A:1007759112499

5. Munyandamutsa N, Nkubamugisha PM, Gex-Fabry M, Eytan A. Mental and physical health in Rwanda 14 years after the genocide. Soc Psychiatry Psychiatr Epidemiol. 2012;47(11):1753-1761. doi:10.1007/s00127-012-0494-9

6. Neugebauer R, Fisher PW, Turner JB, Yamabe S, Sarsfield JA, Stehling-Ariza T. Post-traumatic stress reactions among Rwandan children and adolescents in the early aftermath of genocide. Int J Epidemiol. 2009;38(4):1033-1045. doi:10.1093/ije/dyn375

7. Musanabaganwa C, Jansen S, Fatumo S, et al. Burden of post-traumatic stress disorder in postgenocide Rwandan population following exposure to 1994 genocide against the Tutsi: a meta-analysis. J Affect Disord. 2020;275(December2019):7-13. doi:10.1016/j.jad.2020.06.017

8. Biracyaza E, Habimana S. Contribution of community-based sociotherapy interventions for the psychological well-being of Rwandan youths born to genocide perpetrators and survivors: analysis of the stories telling of a sociotherapy approach. BMC Psychol. 2020;9:1-15. doi:10.1186/s40359-020-00471-9

9. Kagoyire MG, Richters A. "We are the memory representation of our parents ": intergenerational legacies of genocide among descendants of rape survivors in Rwanda. Int Rehabil Counc Torture Vict. 2018;28 (3):30-45. doi:10.7146/torture.v28i3.111183

10. Shrira A, Mollov B, Mudahogora C. Complex PTSD and intergenerational transmission of distress and resilience among Tutsi genocide survivors and their o ff spring: a preliminary report. Psychiatry Res. 2019;271 (November2018):121-123. doi:10.1016/j.psychres.2018.11.040

11. Richters A, Dekker C, Scholte WF. Community based sociotherapy in Byumba, Rwanda. Interventions. 2008;6(2):100-116. doi:10.1097/ WTF.0b013e328307ed33

12. Jansen S, White R, Hogwood J, et al. The "treatment gap" in global mental health reconsidered: sociotherapy for collective trauma in Rwanda. Eur J Psychotraumatol. 2015;6:1-6. doi:10.3402/ejpt.v6.28706

13. Julien-Gauthier F, Jourdan-Ionescu C. Résilience assistée, réussite éducative et réadaptation [Supported Resilience, Educative Success and Re-adaptation]. Ionescu S, editor. De La Résilience Naturelle à La Résilience Assistée[From the Natural Resilience to Supported Resilience]. Presses Universitaires de France; 2015:1-14. Available from: http://lel.crires.ulaval.ca/public/resilience.pdf. French.

14. Kimhi S, Eshel Y. Individual and public resilience and coping with long-term outcomes of war. J Appl Biobehav Res. 2009;14(2):70-89. doi:10.1111/j.1751-9861.2009.00041.x

15. Bonanno GA. Loss, trauma, and human resilience: have we underestimated the human capacity to thrive after extremely aversive events? Am Psychol. 2004;59(1):20-28. doi:10.1037/0003066X.59.1.20

16. Grabbe L, Higgins M, Jordan D, Noxsel L, Gibson B, Murphy J. The Community Resiliency Model $®$ : a pilot of an interoception intervention to increase the emotional self-regulation of women in addiction treatment. Int J Ment Health Addict. 2020;19:793-808. doi:10.1007/ s11469-019-00189-9

17. van der KB. The Body Keeps the Score: Brain, Mind, and Body in the Healing of Trauma. Penguin Books; 2015.
18. Gerbarg P, Wallace G, Brown R. Mass disasters and mind-body solutions: evidence and field insights. Int J Yoga Therap. 2011;21 (1):7-107. doi:10.17761/ijyt.21.1.gn36102834522n07

19. Grabbe L, Craven A, Murphy J, Baird M. Community resiliency model training to improve the well-being OF nurses. 2020.

20. Grabbe L, Higgins M, Edwards A, Craven A, Baird M, Fratello S. Community Resiliency Model ${ }^{\mathbb{B}}$ Training to Improve the Mental WellBeing of Nurses. American psychiatric nurses association; 2018.

21. Grabbe L, Higgins M, Baird M, Craven P, Fratello SS. The Community Resiliency Model $^{\mathbb{B}}$ to promote nurse well-being. Nurs Outlook. 2019;68(3):324-336. doi:10.1016/j.outlook.2019.11.002

22. Grabbe L, Miller-Karas E. The trauma resiliency model: a "bottomup" intervention for trauma psychotherapy. J Am Psychiatr Nurses Assoc. 2018;24(1):76-84. doi:10.1177/1078390317745133

23. Leitch L, Miller-Karas E. A case for using biologically-based mental health intervention in post-earthquake China: evaluation of training in the trauma resiliency model. Int J Emerg Ment Health. 2009;11(4):221-233.

24. Kulig JC, Edge DS, Townshend I, Lightfoot N, Reimer W. Community resiliency: emerging theoretical insights. J Commun Psychol. 2013;41(6):758-775. doi:10.1002/jcop.21569

25. Miller-Karas E. Building Resilience to Trauma: The Trauma and Community Resiliency Models. 1st ed. Routledge; 2015.

26. Miller-Karas E, Citron S. Community resiliency model evaluation, veteran extension project, California mental health services act: final CRM innovation evaluation report; 2013. Available from: https:// www.traumaresourceinstitute.com/research. Accessed July 21, 2021.

27. Barrett ML. The resiliency model. In: The Community Resiliency Model: A Public Health Model for Promoting Health and Healing. Director of Behavioral Health MAHEC Family Health Center; 2018.

28. Grabbe L, Miller-karas E. The trauma resiliency model: a "bottomup”. Interven Trauma Psychother. 2018;24(1):76-84. doi:10.1177/ 1078390317745133

29. Graber R, Pichon F, Carabine E. Psychological resilience: state of knowledge and future research agendas; 2015. Available from: https://www.odi.org/sites/odi.org.uk/files/odi-assets/publicationsopinion-files/9872.pdf. Accessed July 21, 2021.

30. Iacoviello BM, Charney DS. Psychosocial facets of resilience: implications for preventing posttrauma psychopathology, treating trauma survivors, and enhancing community resilience. Eur J Psychotraumatol. 2014;5:1-10. doi:10.3402/ejpt.v5.23970

31. De FC, Blanchet A, Hopkins W, et al. Validation of a French adaptation of the Harvard Trauma Questionnaire among torture survivors from sub-Saharan African countries. Eur J Psychotraumatol. 2012;3 (1):19225. doi:10.3402/ejpt.v3i0.19225

32. Kroenke K, Spitzer RWW, Williams JBW. The Patient Health Questionnaire (PHQ-9): validity of brief depression severity measures. JGIM. 2001;16:606-616. doi:10.1046/j.1525-1497.2001.016009606.x

33. Ting L, Jacobson JM, Bride BE, Harrington D, Harrington D. The Secondary Traumatic Stress Scale (STSS): confirmatory factor analyses with a national sample of mental health social workers. $J$ Hum Behav Soc Environ. 2005;11(3-4):177-193. doi:10.1300/J137v11n03

34. Jacobs I, Charmillot M, Soelch CM, Horsch A. Validity, reliability, and factor structure of the secondary traumatic stress scale-French version. Front Psychiatry. 2019;10(April):191. doi:10.3389/ fpsyt.2019.00191

35. Brogan DR, Kutner MH, Brogan DR, Kutner MH. Comparative analyses of pretest-posttest research designs. Am Stat Assoc. 2016;34(4):229-232.

36. Gishoma D, Brackelaire J-L, Munyandamutsa N, Mujawayezu J, Mohand AA, Kayiteshonga Y; Supportive-Expressive Group. Therapy for people experiencing collective traumatic crisis during the genocide commemoration period in Rwanda: impact and implications. J Soc Polit Psychol. 2014;2(1):469-488. doi:10.5964/jspp.v2i1.292

37. Trauma Resource Institute. Final community resilience model innovation evaluation report; 2013. Available from: https://www.traumar esourceinstitute.com/research. Accessed July 21, 2021. 


\section{Publish your work in this journal}

Psychology Research and Behavior Management is an international, peer-reviewed, open access journal focusing on the science of psychology and its application in behavior management to develop improved outcomes in the clinical, educational, sports and business arenas. Specific topics covered in the journal include: Neuroscience, memory and decision making; Behavior modification and management; Clinical applications; Business and sports performance management; Social and developmental studies; Animal studies. The manuscript management system is completely online and includes a very quick and fair peer-review system, which is all easy to use. Visit http://www. dovepress.com/testimonials.php to read real quotes from published authors. 